\title{
Does thyroid dysfunction affect early mortality and morbidity after coronary artery bypass graft surgery?
}

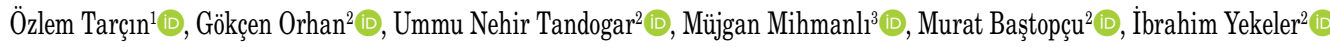 \\ ${ }^{1}$ Department of Endocrinology and Metabolism, Marmara University Medical School, Istanbul, Turkey \\ ${ }^{2}$ Department of Cardiovascular Surgery, Dr. Siyami Ersek Heart and Thoracic Surgery Training and Research Hospital, İstanbul, Turkey \\ ${ }^{3}$ Department of Biochemistery, Dr. Siyami Ersek Heart and Thoracic Surgery Training and Research Hospital, İstanbul, Turkey
}

Received: February 04, 2018 Accepted: February 12, 2018 Published online: April 24, 2019

\begin{abstract}
Objectives: This study aims to evaluate to effect of thyroid dysfunction on early mortality and morbidity in patients undergoing coronary artery bypass grafting (CABG).

Patients and methods: Between April 2008 and December 2010, a total of 37 patients (20 females, 17 males; mean age $54.9 \pm 10.2$ years; range, 26 to 76 years) with thyroid dysfunctions who underwent CABG and 11 patients ( 2 females, 9 males; mean age $46.9 \pm 15.5$ years; range, 26 to 65 years) without thyroid dysfunction who underwent on-pump CABG as the control group were included in the study. Patients were divided into groups as overt and subclinical hypothyroidism, overt hyperthyroidism, and subclinical hyperthyroidism according to the thyroid function test results. The European System for Cardiac Operative Risk Evaluation (EuroSCORE) scores were evaluated and the Gensini severity scores were calculated according to coronary angiographies. All patients were followed for seven days after surgery. The duration of endotracheal intubation, inotropic support, cardiac complications, duration of stay in the intensive care unit (ICU) and hospital were recorded.

Results: There were no statistically significant differences between the groups in terms of the duration of intubation, need of inotropic support, and duration of stay in the ICU and hospital. Arrhythmia was more frequent in the overt hyperthyroid group than in the overt hypothyroid group postoperatively. Thyroid-stimulating hormone (TSH) levels remained unchanged after surgery, whereas free $\mathrm{T}_{3}$ decreased and free $\mathrm{T}_{4}$ increased, which was compatible with postoperative euthyroid sick syndrome. The EuroSCORE scores were positively correlated with pre- and postoperative TSH levels, duration of intubation, and duration of ICU and hospital stay, but was negatively correlated with free $\mathrm{T}_{3}$.

Conclusion: Subclinical or overt thyroid dysfunctions do not seem to affect early mortality after CABG. However, overt hyperthyroidism is associated with postoperative arrhythmia complications. Euthyroid sick syndrome may also occur after surgery in certain cases. Pre- and postoperative TSH and free $\mathrm{T}_{3}$ levels may be useful to identify mortality and morbidity risk in patients undergoing CABG.
\end{abstract}

Keywords: Coronary artery bypass grafting, morbidity, mortality, thyroid dysfunction.

The preoperative thyroid status in patients undergoing coronary artery bypass grafting (CABG) may alter morbidity and mortality during or after surgery by affecting cardiovascular condition and recovery of myocardial function. Potential complications during cardiac surgery due to overt hyperthyroidism and hypothyroidism are well known and well-studied. Hyperthyroidism increases cardiovascular mortality risk due to high rate of supraventricular dysrhythmias, high cardiac output, tachycardia, and decreased systemic vascular resistance.$^{[1,2]}$ Hypothyroidism is another serious risk factor for coronary heart surgery complications ${ }^{[3]}$ which prolongs the cardiac action potential and QT interval, leading to an increased risk of ventricular arrhythmias. ${ }^{[4]}$ Surgery in the setting of overt hyperthyroidism and hypothyroidism should be avoided, if possible, until the patient achieves euthyroid status to prevent peri- and postoperative complications.

Subclinical thyroid dysfunctions have not been widely studied in cardiac surgery patients. In accordance

Corresponding author: Özlem Tarçın, MD. Marmara Üniversitesi Pendik Eğitim ve Araştırma Hastanesi Endokrinoloji ve Metabolizma Hastalıkları Anabilim Dalı, 34899 Pendik, İstanbul, Turkey.

Tel: +90 216 - 4505144 e-mail: ozlemtarcin@yahoo.com

\section{Citation:}

Tarçın Ö, Orhan G, Nehir Tandogar U, Mihmanlı M, Baştopçu M, Yekeler İ. Does thyroid dysfunction affect early mortality and morbidity after coronary artery bypass graft surgery? Cardiovasc Surg Int 2018;5(1):1-8. 
with the current consensus, authors have advocated that subclinical thyroid dysfunction is not a causative factor of surgical complications or mortality. However, no case-controlled study has been reported on the effects of overt or subclinical thyroid dysfunctions on mortality and morbidity after cardiac surgery.

In the present study, we aimed to evaluate early mortality and morbidity in patients with overt and subclinical thyroid dysfunction undergoing CABG.

\section{PATIENTS AND METHODS}

Between April 2008 and December 2010, a total of 37 patients ( 20 females, 17 males; mean age $54.9 \pm 10.2$ years; range, 26 to 76 years) with thyroid dysfunctions who underwent CABG and 11 patients ( 2 females, 9 males; mean age $46.9 \pm 15.5$ years; range, 26 to 65 years) without thyroid dysfunction who underwent on-pump CABG as the control group were included in the study. A written informed consent was obtained from each patient. The study protocol was approved by the local Ethics Committee of Dr. Siyami Ersek Cardiovascular and Thoracic Surgery Training and Research Hospital. The study was conducted in accordance with the principles of the Declaration of Helsinki.

Thyroid status was established by history and clinical examination and confirmed by preoperative thyroid function tests including free $\mathrm{T}_{3}$ (fT3), free T4 ( $\mathrm{fT}_{4}$ ), and thyroid-stimulating hormone (TSH). The patients were divided into groups as overt hypothyroidism $(n=8)$, overt hyperthyroidism $(n=8)$, subclinical hypothyroidism $(\mathrm{n}=11)$, and subclinical hyperthyroidism $(n=10)$ according to their thyroid function test results. The European System for Cardiac Operative Risk Evaluation (EuroSCORE) scores were evaluated and the Gensini severity scores were calculated according to coronary angiographies. Adequate premedication was applied to the patients with overt thyroid dysfunction. The patients with subclinical thyroid dysfunction were followed without any medication for the thyroid status. All patients were followed for the first seven days after surgery in the intensive care unit (ICU) and ward. Duration of endotracheal intubation, need for inotropic support longer than six hour after surgery, cardiac complications such as arrhythmia or infection, duration of stay in the ICU and hospital were recorded. Postoperative thyroid function tests were performed in the first week after surgery.

\section{Assessment of thyroid function}

Serum TSH, $\mathrm{fT}_{3}, \mathrm{fT}_{4}, \mathrm{~T}_{3}$, and $\mathrm{T}_{4}$ concentrations were measured by immunochemiluminometric assay using the Siemens ADVIA Centaur analyzer (Siemens Ltd., Bayswater, Victoria, Australia and Penrose, Auckland, New Zealand-Diagnostics Division, Tarrytown, NY, USA). The percentage coefficient of variation $(\mathrm{CV} \%)$ was $1.7 \%$ at $\mathrm{TSH}$ concentrations of $0.1-0.5 \mathrm{mIU} / \mathrm{L}$ and $2.1 \%$ at $5-10 \mathrm{mIU} / \mathrm{L}$. Normal ranges were between $0.55-4.78 \mathrm{mIU} / \mathrm{L}$ for $\mathrm{TSH} ; 2.3-4.2 \mathrm{pg} / \mathrm{mL}$ for $\mathrm{fT} 3$, and $0.59-1.3 \mathrm{ng} / \mathrm{dL}$ for $\mathrm{fT}_{4}$.

\section{Calculation of EuroSCORE and Gensini scores}

\section{EuroSCORE}

EuroSCORE is a simple, objective, and up-to-date scoring system to predict early mortality based on the objective risk factors in cardiac surgery patients in Europe. ${ }^{[5]}$ The EuroSCORE risk was calculated based on the study of Nashef et al. ${ }^{[6]}$ in all patients. Pointing chart of the scoring system was done according to the risk factors related to the patients and cardiovascular system (CVS) (Table 1). The scoring system was, then, applied to three risk groups. The low-risk group has a score of EuroSCORE 1-2, intermediate-risk group has a score of EuroSCORE 3-5, and the high-risk group has a score of EuroSCORE 6 plus.

\section{Gensini severity scores}

Gensini Severity Index was used to evaluate the severity of atherosclerosis according to coronary angiography (CAG) imaging. In the Gensini's coronary artery scoring method, ${ }^{[7]}$ the geometrically increasing severity of lesions, the cumulative effects of multiple obstructions, the significance of their locations, the modifying influence of the collaterals, and the size and quality of the distal vessels are considered. According to the severity of angiographic stenosis, ratings are as follows: $0-25 \%$ (1), $25-50 \%$ (2), $50-75 \%$ (4), $75-90 \%$ (8), $90-99 \%$ (16), and 100\% (32). All these points are multiplied with coefficient factor for each main vessels and segment. The result is calculated by adding all values.

\section{Statistical analysis}

Statistical analysis was performed using the InStat-GraphPad version 3.10 (GraphPad Software, Inc., San Diego, CA., USA). Descriptive data were expressed in mean \pm standard deviation (SD). Numeric variations were compared using the Student's t-test for 


\begin{tabular}{|c|c|c|c|c|c|c|}
\hline \multicolumn{7}{|c|}{ Table 1} \\
\hline & $\begin{array}{l}\text { Subclinical } \\
\text { hypothyroid } \\
(n=11)\end{array}$ & $\begin{array}{l}\text { Subclinical } \\
\text { hyperthyroid } \\
(n=10)\end{array}$ & $\begin{array}{l}\text { Overt } \\
\text { hypothyroid } \\
(n=8)\end{array}$ & $\begin{array}{l}\text { Overt } \\
\text { hyperthyroid } \\
(n=8)\end{array}$ & $\begin{array}{c}\text { Control } \\
(n=11)\end{array}$ & \\
\hline & Mean \pm SD & Mean \pm SD & Mean \pm SD & Mean \pm SD & Mean \pm SD & $p$ \\
\hline Age (year) & $54.5 \pm 11.2$ & $55.6 \pm 10.2$ & $51.4 \pm 8$ & $58.2 \pm 13.8$ & $46.9 \pm 15.5$ & NS \\
\hline Body mass index & $27.5 \pm 3$ & $26.3 \pm 2.7$ & $27.5 \pm 6.2$ & $28.7 \pm 5.5$ & $25.5 \pm 4.5$ & NS \\
\hline Intubation (hour) & $11.4 \pm 4$ & $16.8 \pm 19.2$ & $14.6 \pm 8$ & $10.3 \pm 1.4$ & $10.3 \pm 3$ & NS \\
\hline ICU stay (hour) & $31.5 \pm 29.4$ & $30.7 \pm 23$ & $40.6 \pm 27.8$ & $37 \pm 23$ & $28.8 \pm 14.3$ & NS \\
\hline Hospital stay (day) & $7.9 \pm 2.9$ & $7.7 \pm 2$ & $7.4 \pm 1.4$ & $8.3 \pm 1.4$ & $8.4 \pm 3.4$ & NS \\
\hline
\end{tabular}

independent samples or by the Mann-Whitney test. The chi-square test or Fisher's exact test, if applicable, were used to compare the groups. The Pearson's correlation analysis was used for the comparison of variables. A $p$ value of $<0.05$ was considered statistically significant.

\section{RESULTS}

The baseline demographic and clinical characteristics of study groups are summarized in Table 2. There was no significant difference in the mean age and body mass index (BMI) between the groups. However, duration of ICU stay was slightly longer in the patients with overt thyroid dysfunction, although not statistically significant. Duration of endotracheal intubation and hospital stay were not significantly different between the groups. Although arrhythmia was more evident in the overt hyperthyroid group than in the overt hypothyroid group postoperatively, there was no significant difference between the groups in terms of the need of inotropic support and postoperative complications such as infection. According to the operation, the patients who underwent concomitant valve and CABG needed more inotropic support postoperatively, as expected, due to the distinct physiopathology of valvular diseases.

When pre- and postoperative thyroid function tests were compared between the groups (Table 3), TSH was not found to change significantly after surgery. However, in patients with subclinical thyroid dysfunctions, $\mathrm{fT}_{3}$ decreased and $\mathrm{fT}_{4}$ increased significantly, whereas only $\mathrm{fT}_{3}$ decreased in the overt hypothyroidism group and only $\mathrm{fT}_{4}$ increased in the overt hyperthyroid and control groups, suggesting postoperative euthyroid sick syndrome.

\begin{tabular}{|c|c|c|c|c|c|c|}
\hline \multicolumn{7}{|c|}{$\begin{array}{c}\text { Table } 2 \\
\text { Pre- and postoperative thyroid function test results }\end{array}$} \\
\hline & \multicolumn{3}{|c|}{ Preoperative } & \multicolumn{3}{|c|}{ Postoperative } \\
\hline & $\mathrm{TSH}$ & $\mathrm{fT}_{3}$ & $\mathrm{fT}_{4}$ & $\mathrm{TSH}$ & $\mathrm{fT}_{3}$ & $\mathrm{fT}_{4}$ \\
\hline & Mean $\pm S D$ & Mean \pm SD & Mean \pm SD & Mean \pm SD & Mean \pm SD & Mean \pm SD \\
\hline Subclinical hypothyroid & $7.3 \pm 1.6$ & $2.9 \pm 0.5^{*}$ & $0.9 \pm 0.3^{*}$ & $6.8 \pm 3.4$ & $2.5 \pm 0.4$ & $1.2 \pm 0.3$ \\
\hline Subclinical hyperthyroid & $0.15 \pm 0.1$ & $3 \pm 0.6^{*}$ & $1.1 \pm 0.3^{*}$ & $0.19 \pm 0.2$ & $2.5 \pm 0.5$ & $1.3 \pm 0.4$ \\
\hline Overt hypothyroid & $16.5 \pm 8.2$ & $2.8 \pm 0.7^{*}$ & $0.7 \pm 0.2$ & $15.3 \pm 10.2$ & $2.1 \pm 0.6$ & $0.8 \pm 0.3$ \\
\hline Overt hyperthyroid & $0.03 \pm 0.03$ & $3.3 \pm 0.6$ & $1.2 \pm 0.3^{*}$ & $0.04 \pm 0.05$ & $3.5 \pm 0.9$ & $1.8 \pm 0.6$ \\
\hline Control & $1.7 \pm 0.6$ & $2.9 \pm 0.3$ & $1 \pm 0.17^{*}$ & $1.7 \pm 0.8$ & $2.8 \pm 0.4$ & $1.2 \pm 0.2$ \\
\hline
\end{tabular}

TSH: Thyroid-stimulating hormone; $\mathrm{fT}_{3}$ : Free $\mathrm{T}_{3} ; \mathrm{fT}_{4}$ : Free $\mathrm{T}_{4}$; SD: Standard deviation; ${ }^{*} \mathrm{p}<0.05$ correlated with postoperative values. 


\begin{tabular}{|c|c|c|}
\hline \multicolumn{3}{|c|}{$\begin{array}{l}\text { Correlation of EuroSCORE scores with thyroid function } \\
\text { test results }(\mathrm{n}=48)\end{array}$} \\
\hline & $\begin{array}{r}\text { Pearson's corr } \\
\text { coefficie }\end{array}$ & \\
\hline & $\mathrm{r}$ & $p$ \\
\hline Preoperative TSH & 0.42 & 0.004 \\
\hline Preoperative $\mathrm{fT}_{3}$ & -0.38 & 0.01 \\
\hline Preoperative $\mathrm{fT}_{4}$ & -0.28 & 0.06 \\
\hline Postoperative TSH & 0.30 & 0.05 \\
\hline Postoperative $\mathrm{fT}_{3}$ & -0.42 & 0.006 \\
\hline Postoperative $\mathrm{fT}_{4}$ & -0.26 & 0.08 \\
\hline
\end{tabular}

TSH: Thyroid-stimulating hormone.

The EuroSCORE and Gensini severity scores were evaluated for all study groups. The mean EuroSCORE score was 2.25 for overt hyperthyroidism, 5.75 for overt hypothyroidism, 3.6 for subclinical hyperthyroidism, 3.81 for subclinical hypothyroidism, and 2.18 for the control group. There was no statistically significant difference between the groups. However, we found a positive and significant correlation of EuroSCORE with preoperative TSH levels $(\mathrm{p}=0.004 ; \mathrm{r}=0.42)$, postoperative TSH levels $(\mathrm{p}=0.05 ; \mathrm{r}=0.30)$, duration of intubation $(p=0.04 ; r=0.31)$, ICU stay $(p<0.005$; $\mathrm{r}=0.49)$, and hospital stay $(\mathrm{p}=0.01 ; \mathrm{r}=0.37)$, but negatively and significantly correlated with the preoperative $\mathrm{fT}_{3}$ levels $(\mathrm{p}=0.01 ; \mathrm{r}=-0.38)$ and postoperative $\mathrm{fT}_{3}$ levels $(\mathrm{p}=0.006 ; \mathrm{r}=-0.42)$ (Table 4) (Figure 1). Pre- and postoperative fT4 levels were negatively correlated with the EuroSCORE, but were not statistically significant $(p=0.06 ; r=-0.28$ and $\mathrm{p}=0.08 ; \mathrm{r}=-0.26$, respectively). The Gensini severity scores were 106.6 for overt hyperthyroidism, 69.5 for overt hypothyroidism, 81.8 for subclinical hyperthyroidism, 62 for subclinical hypothyroidism,
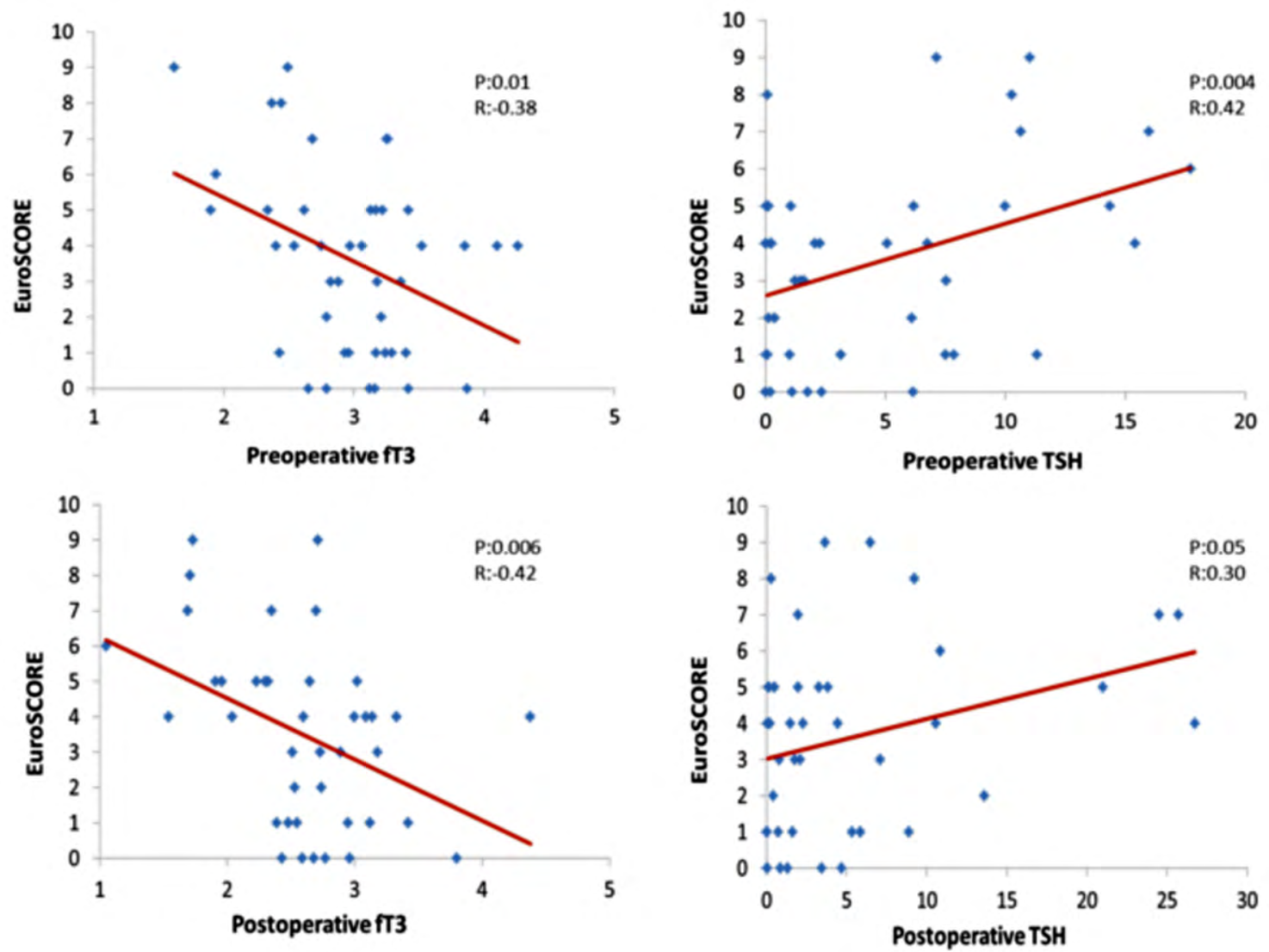

Figure 1. Correlation of EuroSCORE with pre- and postoperative $\mathrm{fT}_{3}$ and $\mathrm{TSH}$ levels.

TSH: Thyroid-stimulating hormone; $\mathrm{fT}_{3}$ : Free $\mathrm{T}_{3}$. 
and 74 for the control group. However, there was no significant difference between the groups and no correlation between the Gensini scores and thyroid function test results or other follow-up parameters.

\section{DISCUSSION}

Thyroid hormones have various effects on the CVS which are mediated at both genomic and non-genomic levels. ${ }^{[8]}$ Overt hyperthyroidism has well-known effects on the CVS such as resting tachycardia, arrhythmias (most commonly supraventricular), thromboembolism, and heart failure which may lead to cardiovascular and cerebrovascular mortality, particularly in patients with CVS diseases. ${ }^{[1,2]}$ Most feared perioperative complication is thyroid storm which may occur anytime in the perioperative period with a mortality rate of 10 to $75 \% .{ }^{[9]}$ Paroxysmal atrial fibrillation is also a serious complication of hyperthyroidism which may occur at least once in nearly $25 \%$ of cases. ${ }^{[10]}$ In addition, the combination of tachycardia and hypertension may precipitate angina or myocardial infarction in patients with underlying coronary artery diseases. ${ }^{[11,12]}$ In particular, untreated Graves' disease, which is more prominent and aggressive, may cause fatal results in these patients.

There are some reported cases with hyperthyroidism undergoing open heart surgery with or without premedication. Onoe et al. ${ }^{[13]}$ reported that, in two patients with known thyrotoxicosis, open heart surgery was successfully performed by preoperative and early postoperative anti-thyroid agents. However, in a recent article, Bish et al. ${ }^{[14]}$ found thyroid storm developing in a patient after urgent $\mathrm{CABG}$ caused by Graves' disease which was unknown before surgery and controlled by immediate potassium iodide and thionamides through nasogastric tube, as well as high-dose intravenous hydrocortisone. In our study, we found no increase in the mortality rate in overt hyperthyroid patients, although we observed increased arrhythmia in this patient group after surgery, compared to the hypothyroid group, which was not statistically significant.

Similarly, overt hypothyroidism may cause many of the signs and symptoms associated with heart failure including dyspnea, edema, cardiomegaly, and effusions and increase the risk of coronary artery disease. ${ }^{[3]}$ However, these patients have a lower incidence of angina and myocardial infection, perhaps secondary to the reduction in cardiac metabolic demands. The patients usually have hypertension due to alterations in the peripheral vascular resistance and an increased risk of ventricular arrhythmias. ${ }^{[4]}$ In untreated overt hypothyroidism patients, acute thyroid hormone replacement therapy may worsen myocardial ischemia due to increased myocardial oxygen consumption. ${ }^{[15]}$ There are still conflicting data regarding the safety of CABG in untreated patients. Some authors have reported no adverse effects in patients with untreated mild-to-moderate hypothyroidism undergoing cardiac surgery, ${ }^{[16-18]}$ whereas some others have suggested adverse effects such as severe myxedema after cardiac surgery, leading to significant hemodynamic compromise. ${ }^{[19]}$ Some reports have also shown that percutaneous transluminal coronary angioplasty (PTCA) can be a better choice before CABG in hypothyroid patients who have a higher incidence of complications, if there is no time to render them euthyroid. ${ }^{[20,21]}$ In our study, one patient with overt hypothyroidism who was operated emergently died due to critical coronary obstruction and aortic valve failure. However, the incidence of other complications was not higher in the overt hypothyroid patients, compared to the control group.

Subclinical thyroid diseases continue to be an issue in the preoperative evaluation of patients and are more common than overt thyroid disorders. The prevalence ranges between 2 and $8 \%$ in the general population and higher in women over the age of $60 .{ }^{[22]}$ Subclinical thyroid dysfunctions may develop after a contrast agent administration during PTCA or CAG. ${ }^{[23]}$ In a recent study Marraccini et al. ${ }^{[24]}$ reported that thyroid dysfunction was frequent in patients who underwent $\mathrm{CAG}$, and low $\mathrm{T}_{3}$ syndrome was the predominant feature in these patients. Furthermore, in patients with valvular heart diseases, euthyroid sick syndrome (low $\mathrm{T}_{3}$ syndrome) is a common problem, particularly who have heart failure and affects mortality. ${ }^{[25,26]}$ Thus, patients with subclinical thyroid dysfunction should be investigated in detail about exposure of the contrast agents, family history of thyroid diseaßses, diseases affecting blood circulation, and the use of inotropic drugs which leads to decreased TSH.

In the literature, there are few studies and case reports which are controversial regarding the safety of cardiac surgery in subclinical thyroid diseases. Mantzoros et al. ${ }^{[27]}$ revealed that subclinical hypothyroidism did not appear to be a risk factor for significant morbidity or increased mortality following PTCA. Ripoli et al. ${ }^{[28]}$ examined the 
effects of subclinical hypothyroidism on the cardiac pump performance and found that subclinical hypothyroidism decreased the end-diastolic volume and increased systemic vascular resistance, leading to impairment of the cardiac pump performance, compared to healthy subjects. More importantly, the incidence of transient atrial fibrillation after CABG was found to be slightly higher in patients with subclinical hypothyroidism. ${ }^{[29]}$ This finding suggests that the detection of preoperative thyroid dysfunction or the routine assessment of thyroid function may be useful for patients undergoing CABG. In our study, there was no significant difference between the subclinical hypothyroid or hyperthyroid patients and control group in terms of the morbidity and surgery complication rates.

The EuroSCORE is a simple and common risk scoring system for predicting operative mortality. ${ }^{[6,30]}$ Gensini severity scoring system is also commonly used to identify the severity of coronary artery stenosis according to CAG. ${ }^{[7]}$ To the best of our knowledge, correlation of these risk scores and thyroid function test results has not been studied in the literature, yet. In this study, we were unable to find a significant correlation between the Gensini scores and any of the thyroid function test results. However, the EuroSCORE scores were positively correlated with the pre- and postoperative TSH levels and negatively correlated with the pre- and postoperative $\mathrm{fT}_{3}$ levels and slightly correlated with $\mathrm{fT}_{4}$ levels. The correlations were more evident for $\mathrm{fT}_{3}$ and $\mathrm{TSH}$, followed by $\mathrm{fT}_{4}$, suggesting that mortality increases with high TSH and low $\mathrm{fT}_{3}$ levels. That is why preoperative thyroid function test should be routinely performed and may be useful postoperatively in predicting mortality, in particular in patients with a known thyroid disease.

Euthyroid sick syndrome and low $\mathrm{T}_{3}$ syndrome are also well-described after cardiac surgery. In severe stress or major surgery, circulating levels of T3 decrease within two hours which is thought to reflect a reduction in the peripheral conversion of $\mathrm{T}_{4}$ to $\mathrm{T}_{3} \cdot{ }^{[31,32]}$ The majority of studies investigating thyroid hormone levels in patients undergoing cardiac surgery have demonstrated a well-established reduction in the fT3 levels, particularly under cardiopulmonary bypass. ${ }^{[33-35]}$ Murzi et al. ${ }^{[35]}$ showed a significant reduction in the $\mathrm{fT}_{3}$ levels with a nadir at $48 \mathrm{~h}$ postoperatively and that the levels were still below baseline values at up to six days following surgery. The degree of the decline in the $\mathrm{fT}_{3}$ levels was higher than the $\mathrm{fT}_{4}$ levels.
Similarly, in our study, we found a decline in the $\mathrm{fT}_{3}$ levels on postoperative Days 5-7 and reduction of $\mathrm{fT}_{3}$ levels were more prominent than the fT4 levels. Postoperative low $\mathrm{T}_{3}$ syndrome decreases cardiac output as in chronic hypothyroidism and systemic vascular resistance increases. ${ }^{[36]}$ Recent studies have mostly addressed into the effects of postoperative $T_{3}$ replacement therapy. Previous studies performed in small study groups have shown that $\mathrm{T}_{3}$ replacement therapy increases cardiac output, decreases the need for inotropic agents and incidence of atrial fibrillation after cardiac surgery. ${ }^{[34,37,38]}$ Although it has been shown that $T_{3}$ replacement therapy decreases the incidence of arrhythmia by improving hemodynamic performance, its association with mortality has not been established in large-scale, randomized-controlled studies, yet. ${ }^{[39-41]}$ In a clinical review, Kaptein et al. ${ }^{[41]}$ analyzed 14 randomized-controlled studies involving patients undergoing cardiac surgery and reported that, although cardiac index increased and the need for inotropic agents decreased, particularly in elderly patients with low ejection fraction values with $T_{3}$ replacement therapy, there was no significant difference in the mortality rates. On the other hand, there is a limited number of data regarding the duration of stay in the ICU and hospital. In our study, the complication risk did not significantly decrease in the patients, even if the $\mathrm{fT}_{3}$ levels decreased. The strong association between the EuroSCORE scores and $\mathrm{fT}_{3}$ and $\mathrm{TSH}$ levels suggests that $\mathrm{T}_{3}$ replacement therapy may have positive effects on mortality. Based on these findings, we suggest that certain patients with low $\mathrm{T}_{3}$ and high TSH levels in the postoperative period may benefit from $\mathrm{T}_{3}$ replacement therapy. However, further studies including the mortality endpoint is required to investigate the possible benefits of thyroid hormone replacement.

Most reviewers and authors recommend premedication for overt hyperthyroidism to prevent thyroid storm or other complications during the perioperative period. ${ }^{[42-44]}$ For patients with uncontrolled hyperthyroidism who are candidates for an elective surgery, surgical procedure should be postponed, until they become stable on antithyroid therapy. For patients presenting urgent or emergent surgery, the anesthesiologist should be informed about the patent's status to have drugs which block the systematic effects of thyroid hormones such as beta-blockers, iodide, and thionamides ready. Although premedication for hyperthyroidism is clear 
in general, there is still controversy for hypothyroid patients with known ischemic heart diseases or those who are candidates for coronary revascularization. Rapid treatment of thyroid dysfunction may increase myocardial oxygen demand, leading to ischemia. Currently, the consensus is that, if a patient needs urgent cardiac revascularization, they should undergo the procedure before replacement therapy; ${ }^{[44,46]}$ however, many endocrinologists prefer starting lowdose $T_{4}$ treatment in hospitalized patients. In our overt hyperthyroid patients, we started oral thionamides before surgery, although overt hypothyroid patients underwent surgery, particularly those who had critical coronary stenosis. Our common idea was that revascularization is more important than hypothyroidism, as at least four weeks are needed to render those patients in the euthyroid state. Unfortunately, one of our overt hypothyroid patients with severe coronary artery stenosis and aortic valve stenosis who underwent emergent surgery died.

The main limitation of our study is its small sample size. In addition, total thyroid function test was not performed in this study, as free thyroid hormone levels are more reliable in this study population. In our study, for the first time, thyroid function tests were correlated with coronary artery stenosis risk scores and surgical mortality scores such as Gensini and EuroSCORE. Also, subclinical thyroid disorders were evaluated in patients undergoing CABG for the first time in a controlled study. Nonetheless, further largescale, prospective, randomized-controlled studies are needed to confirm these findings.

In conclusion, $\mathrm{CABG}$ seems to be safe in patients with thyroid dysfunction. Overt hyperthyroidism increases the risk of arrhythmia and other potential complications due to hyperthyroidism. Conversely, subclinical thyroid disorders are not associated with any complications and there is no need for premedication before and after CABG. The EuroSCORE scores also increase with low $\mathrm{fT}_{3}$ and high TSH levels in the perioperative period, suggesting that thyroid hormones may affect open heart surgery-related mortality or morbidity rates and should be, therefore, evaluated before and after surgery. Based on our study findings, $\mathrm{T}_{3}$ replacement therapy may be useful in patients with low $\mathrm{fT}_{3}$ and high TSH levels who have a higher mortality risk score, according to the EuroSCORE.

\section{Declaration of conflicting interests}

The authors declared no conflicts of interest with respect to the authorship and/or publication of this article.

\section{Funding}

The authors received no financial support for the research and/or authorship of this article.

\section{REFERENCES}

1. Osman F, Gammage MD, Franklyn JA. Hyperthyroidism and cardiovascular morbidity and mortality. Thyroid 2002;12:483-7.

2. Parle JV, Maisonneuve P, Sheppard MC, Boyle P, Franklyn JA. Prediction of all-cause and cardiovascular mortality in elderly people from one low serum thyrotropin result: a 10-year cohort study. Lancet 2001;358:861-5.

3. Auer J, Berent R, Weber T, Lassnig E, Eber B. Thyroid function is associated with presence and severity of coronary atherosclerosis. Clin Cardiol 2003;26:569-73.

4. Ojamaa K, Sabet A, Kenessey A, Shenoy R, Klein I. Regulation of rat cardiac Kv1.5 gene expression by thyroid hormone is rapid and chamber specific. Endocrinology 1999;140:3170-6.

5. Sá MP, Soares EF, Santos CA, Figueredo OJ, Lima RO, Escobar RR, et al. EuroSCORE and mortality in coronary artery bypass graft surgery at Pernambuco Cardiologic Emergency Medical Services [Pronto Socorro Cardiológico de Pernambuco]. Rev Bras Cir Cardiovasc 2010;25:474-82.

6. Nashef SA, Roques F, Michel P, Gauducheau E, Lemeshow S, Salamon R. European system for cardiac operative risk evaluation (EuroSCORE). Eur J Cardiothorac Surg 1999;16:9-13.

7. Gensini GG. A more meaningful scoring system for determining the severity of coronary heart disease. Am J Cardiol 1983;51:606.

8. Danzi S, Klein I. Thyroid hormone-regulated cardiac gene expression and cardiovascular disease. Thyroid 2002;12:467-72.

9. Ringel MD. Management of hypothyroidism and hyperthyroidism in the intensive care unit. Crit Care Clin 2001;17:59-74.

10. Wiklund RA, Rosenbaum SH. Thyroid dysfunction in the preoperative period. Curr Opin Anaesthesiol 1997;10:244-7.

11. Phull PS, Collins CE, Norell MS, Thomas DJ. Variant angina in thyrotoxicosis. Br J Clin Pract 1993;47:17-8.

12. Glikson M, Freimark D, Leor R, Shechter M, Kaplinsky E, Rabinowitz B. Unstable anginal syndrome and pulmonary oedema due to thyrotoxicosis. Postgrad Med J 1991;67:81-3.

13. Onoe M, Magara T, Yamamoto Y, Nojima T. Cardiac surgery for the patients with hyperthyroidism. Kyobu Geka 1998;51:388-91. [Abstract]

14. Bish LT, Bavaria JE, Augoustides J. Thyroid storm after coronary artery bypass grafting. J Thorac Cardiovasc Surg 2010;140:67-9.

15. Bennett-Guerrero E, Kramer DC, Schwinn DA. Effect of chronic and acute thyroid hormone reduction on perioperative outcome. Anesth Analg 1997;85:30-6. 
16. Jones TH, Hunter SM, Price A, Angelini GD. Should thyroid function be assessed before cardiopulmonary bypass operations? Ann Thorac Surg 1994;58:434-6.

17. Drucker DJ, Burrow GN. Cardiovascular surgery in the hypothyroid patient. Arch Intern Med 1985;145:1585-7.

18. Syed AU, El Watidy AF, Akhlaque NB, Wahba A, El Oakley $\mathrm{RM}$, Imran $\mathrm{K}$, et al. Coronary bypass surgery in patients on thyroxin replacement therapy. Asian Cardiovasc Thorac Ann 2002;10:107-10.

19. O'Connor CJ, March R, Tuman KJ. Severe myxedema after cardiopulmonary bypass. Anesth Analg 2003;96:62-4.

20. Sherman SI, Ladenson PW. Percutaneous transluminal coronary angioplasty in hypothyroidism. Am J Med 1991;90:367-70.

21. Stathatos N, Wartofsky L. Perioperative management of patients with hypothyroidism. Endocrinol Metab Clin North Am 2003;32:503-18.

22. Vanderpump MP. The epidemiology of thyroid disease. $\mathrm{Br}$ Med Bull 2011;99:39-51.

23. Özkan S, Oysu AS, Kayataş K, Demirtunç R, Eren M, Uslu $\mathrm{H}$, et al. Thyroid functions after contrast agent administration for coronary angiography: a prospective observational study in euthyroid patients. Anadolu Kardiyol Derg 2013;13:363-9.

24. Marraccini P, Bianchi M, Bottoni A, Mazzarisi A, Coceani M, Molinaro S, et al. Prevalence of thyroid dysfunction and effect of contrast medium on thyroid metabolism in cardiac patients undergoing coronary angiography. Acta Radiol 2013;54:42-7.

25. Ascheim DD, Hryniewicz K. Thyroid hormone metabolism in patients with congestive heart failure: the low triiodothyronine state. Thyroid 2002;12:511-5.

26. Pingitore A, Landi P, Taddei MC, Ripoli A, L'Abbate A, Iervasi $G$. Triiodothyronine levels for risk stratification of patients with chronic heart failure. Am J Med 2005;118:132-6.

27. Mantzoros CS, Evagelopoulou K, Moses AC. Outcome of percutaneous transluminal coronary angioplasty in patients with subclinical hypothyroidism. Thyroid 1995;5:383-7.

28. Ripoli A, Pingitore A, Favilli B, Bottoni A, Turchi S, Osman NF, et al. Does subclinical hypothyroidism affect cardiac pump performance? Evidence from a magnetic resonance imaging study. J Am Coll Cardiol 2005;45:439-45.

29. Park YJ, Yoon JW, Kim KI, Lee YJ, Kim KW, Choi SH, et al. Subclinical hypothyroidism might increase the risk of transient atrial fibrillation after coronary artery bypass grafting. Ann Thorac Surg 2009;87:1846-52.

30. Roques F, Nashef SA, Michel P, Gauducheau E, de Vincentiis C, Baudet E, et al. Risk factors and outcome in European cardiac surgery: analysis of the EuroSCORE multinational database of 19030 patients. Eur J Cardiothorac Surg 1999;15:816-22.

31. Chopra IJ, Huang TS, Beredo A, Solomon DH, Chua Teco GN, Mead JF. Evidence for an inhibitor of extrathyroidal conversion of thyroxine to 3,5,3'-triiodothyronine in sera of patients with nonthyroidal illnesses. J Clin Endocrinol Metab 1985;60:666-72.

32. Van den Berghe G. The neuroendocrine response to stress is a dynamic process. Best Pract Res Clin Endocrinol Metab 2001;15:405-19.

33. Bremner WF, Taylor KM, Baird S, Thomson JE, Thomson JA, Ratcliffe JG, et al. Hypothalamo-pituitary-thyroid axis function during cardiopulmonary bypass. J Thorac Cardiovasc Surg 1978;75:392-9.

34. Klemperer JD, Klein I, Gomez M, Helm RE, Ojamaa K, Thomas SJ, et al. Thyroid hormone treatment after coronaryartery bypass surgery. N Engl J Med 1995;333:1522-7.

35. Murzi B, Iervasi G, Masini S, Moschetti R, Vanini V, Zucchelli G, et al. Thyroid hormones homeostasis in pediatric patients during and after cardiopulmonary bypass. Ann Thorac Surg 1995;59:481-5.

36. Klein I, Ojamaa K. Thyroid hormone and the cardiovascular system. N Engl J Med 2001;344:501-9.

37. Novitzky D, Cooper DK, Swanepoel A. Inotropic effect of triiodothyronine (T3) in low cardiac output following cardioplegic arrest and cardiopulmonary bypass: an initial experience in patients undergoing open heart surgery. Eur J Cardiothorac Surg 1989;3:140-5.

38. Novitzky D, Cooper DK, Barton CI, Greer A, Chaffin J, Grim J, et al. Triiodothyronine as an inotropic agent after open heart surgery. J Thorac Cardiovasc Surg 1989;98:972-7.

39. Mullis-Jansson SL, Argenziano M, Corwin S, Homma S, Weinberg AD, Williams $\mathrm{M}$, et al. A randomized doubleblind study of the effect of triiodothyronine on cardiac function and morbidity after coronary bypass surgery. J Thorac Cardiovasc Surg 1999;117:1128-34.

40. Bennett-Guerrero E, Jimenez JL, White WD, D'Amico EB, Baldwin BI, Schwinn DA. Cardiovascular effects of intravenous triiodothyronine in patients undergoing coronary artery bypass graft surgery. A randomized, double-blind, placebo- controlled trial. Duke T3 study group. JAMA 1996;275:687-92.

41. Kaptein EM, Sanchez A, Beale E, Chan LS. Clinical review: Thyroid hormone therapy for postoperative nonthyroidal illnesses: a systematic review and synthesis. J Clin Endocrinol Metab 2010;95:4526-34.

42. Spell NO. Stopping and restarting medications in the perioperative period. Med Clin North Am 2001;85:1117-28.

43. Prescott PT. Disorders of the thyroid. In: Lubin MF, Smith RB, Dodson TF, Spell NO, Walker HK, editors. Medical management of the surgical patient. Cambridge: Cambridge University Press; 2006. p. 367-73.

44. Mckeown NJ, Tews MC, Gossain VV, Shah SM. Hyperthyroidism. Emerg Med Clin North Am 2005;23:669-85.

45. Connery LE, Coursin DB. Assessment and therapy of selected endocrine disorders. Anesthesiol Clin North America 2004;22:93-123.

46. Schiff RL, Welsh GA. Perioperative evaluation and management of the patient with endocrine dysfunction. Med Clin North Am 2003;87:175-92. 